\title{
Measuring the Structural Credibility of Monetary Policy by Expected Inflation Determinants: A Kalman Filter Approach for Brazil ${ }^{*}$
}

\author{
Ricardo Ramalhete Moreira $^{* *}$
}

\begin{abstract}
This paper proposes an extension to Moreira's (2013a,b) approach as a method for measuring the structural credibility of monetary policy under inflation-targeting regimes using the main determinants of expected inflation and Kalman filtering with calibration parameters. Such a method is exempted from some of the restrictions found in existing credibility indexes, such as in Cecchetti and Krause (2002). The proposed approach was applied to the Brazilian case as an illustration and yielded robust results, demonstrating that there exists a mutual dynamic relationship between expected inflation, observed inflation, and credibility behavior over time.
\end{abstract}

Keywords: Monetary policy credibility, Expected inflation, Kalman filter, Brazil.

JEL Codes: E310, E37, E58.

\footnotetext{
${ }^{*}$ Submitted in October 2015. Revised in July 2016.

** Professor, Programa de Pós-Graduação em Economia, UFES, Brazil. E-mail: ricardo. moreira@ufes.br
}

Brazilian Review of Econometrics

v. $36, \mathrm{n}^{\circ} 2$, pp. $287-309 \quad$ November 2016 


\section{Introduction}

Expected inflation is a relevant variable when Central Banks adjust basic interest rates. As expected inflation is one of the effective determinants of inflation, which is clear by a simple new Keynesian Phillips curve (Clarida et al., 1999, Svensson, 2000), the higher the expected inflation, the higher the social costs from reacting to inflation shocks. Additionally, expected inflation is an important variable that determines expected short-term interest rates, and thus the long-term interest rate, thereby causing dramatic effects on the output dynamics (Woodford, 2003). Moreover, the expected inflation dynamics can provide information on monetary policy credibility, as the latter depends on the weight of inflation targets (and of the lagged inflation) on expected inflation (Lalonde, 2005, Moreira, 2013a).

Therefore, given that inflation expectations are important in many aspects, it is not surprising that there exists a recent literature aimed at explaining the expected inflation phenomenon theoretically and, at the same time, at investigating the empirical correlation and/or causality between such a phenomenon and lagged inflation, output dynamics, exchange rates, among others. Indeed, the empirical specification of the expected inflation dynamics strongly depends on the theoretical specification of actual inflation (more specifically, the Phillips curve), if the rational expectations hypothesis is assumed into the reference model.

In turn, several developing economies have adopted the inflation-targeting regime over the last decades as a way to control inflation rates and anchor inflation expectations. Brazil, in particular, has used inflation targets since 1999. However, the Brazilian Central Bank (BCB) has not achieved the inflation target (4.5\% according to the Broad Consumer Price Index) in the past years; therefore, the monetary authorities' reputation can be presumably lost, thereby increasing disinflation costs. This can occur because deviations of the effective inflation around the inflation target affect monetary policy credibility, that is, they make expected inflation more sensitive to the observed or lagged inflation dynamics and, therefore, less anchored on the inflation target (Moreira, 2013b). Thus, measuring the short- and long-term relationship between expected inflation and other relevant variables is useful in assessing monetary policy structural credibility, as well as in informing how to control inflation expectations.

This work presents a method to measure monetary policy credibility by means of a time-varying or Kalman filter approach, applying it to the Brazilian case as an illustration. As it will be argued, the existing indexes that measure monetary policy credibility, such as in Cecchetti and Krause (2002), among others, have some methodological disadvantages. The current analysis builds upon the study by Moreira (2013a,b) and overcomes those methodological problems, such as the imposition of ad hoc boundaries to the range of values that can be assumed by the degree of credibility. Instead, the current approach does not impose such restrictions "allowing the data to speak more directly about alternative expectations 
hypothesis" (Fuhrer, 1992, p. 176). Fuhrer (op.cit.) proposed a seminal method applied to expectations behavior based on a model in which money growth was the main instrument of the US monetary policy, and the credibility of such policy could be inferred by the weight of the Fed's announcements of money growth on expectations. In turn, the current approach is mainly applied to inflation-targeting regimes (although it is feasible for countries that implicitly target consumer inflation), in which the basic interest rate is the main instrument of monetary policy and credibility can be inferred by the weight of announced (or implicit) inflation targets on inflation expectations.

The remainder of this paper is organized as follows: Section 2 presents the theoretical aspects and some related empirical results. Section 3 presents the data, the empirical strategy, and the analysis of results, as well as the ways by which we tested for their robustness. Finally, the concluding remarks, references, and a statistical appendix are presented.

\section{Related Literature}

\section{$2.1 \quad$ Theoretical aspects}

Controlling expected inflation rates is an important aspect in the monetary policy literature. Basically, if the Central Bank aims to control inflation dynamics at lower output costs, managing inflation expectations efficiently is a necessary requirement. Such a management requires a credible commitment from the Central Bank so that the economic agent's expected inflation relies heavily on the announced target. There is a specific literature on the properties of monetary policy credibility and its impacts on macroeconomic performance and policy efficiency (see Argov et al., 2007, Lalonde, 2005, Moreira, 2013a).

Under inflation-targeting regimes, particularly when the Central Bank is restricted by a low degree of credibility, expected inflation becomes more sensitive to past inflation and, consequently, less dependent on the Central Bank's announced goals. In such a situation, disinflation requires higher interest rates and thereby a larger output sacrifice. According to (Moreira, 2013a, p. 5), "Central banks with lower (higher) degree of credibility are constrained (benefited) by an inflationary dynamics which is more (less) sensitive to past inflation, that is, in such a case there is more (less) inertia in the inflationary process." Thus, measuring credibility is a fundamental step for one to assess disinflation costs. Cecchetti and Krause (2002) propose the following credibility index $(C)$ :

$$
\begin{gathered}
\text { If } E(\pi) \leq \pi^{*} \text { then } C=1 ; \\
\text { If } \pi^{*}<E(\pi)<20 \% \text { then } C=1-\left[1 /\left(0.2-\pi^{*}\right)\right]\left[E(\pi)-\pi^{*}\right] ; \\
\text { And if } E(\pi)>20 \% \text { then } C=0 .
\end{gathered}
$$

Let $E(\pi)$ stand for inflation expectations and $\pi^{*}$ for the inflation target. Hence, credibility varies from 0 to 1 depending on deviations of expected inflation around 
the target, with ad hoc maximum limit for expected inflation of $20 \%$ per year as the condition for zero credibility. In turn, De Mendonça (2004) presents a credibility index that can be applied to economies with inflation intervals above and below the target band:

$$
\begin{gathered}
\text { If } E(\pi)=\pi^{*} \text { then } C=1 ; \\
\text { If } \pi_{\text {Min }}^{*}<E(\pi)<\pi_{\text {Max }}^{*} \text { then } C=1-\left[1 /\left(\pi_{\text {Max }}^{*}-\pi^{*}\right)\right]\left[E(\pi)-\pi^{*}\right] ;
\end{gathered}
$$

And if $E(\pi) \geq \pi_{M a x}^{*}$ or $E(\pi) \leq \pi_{\text {Min }}^{*}$ then $C=0$.

In such case, when inflation expectations are above the maximum inflation target level $\left(\pi_{M a x}^{*}\right)$ or below the minimum inflation target level $\left(\pi_{\text {Min }}^{*}\right)$, the credibility index is equal to zero. According to this method, any shock pushing inflation expectations beyond those limits is translated into zero credibility, even if firms and households evaluate monetary policy as credible over time.

\section{An alternative approach}

These indexes measuring monetary policy credibility require certain ad hoc limits to be imposed in order to allow them to vary between 0 and 1 . Alternatively, Moreira (2013a) presents a model in which the degree of credibility is concomitantly a dependent and an explanatory variable in the macroeconomic dynamics.

Therefore, two specific situations would be possible: the degree of credibility would be equal to unity if lagged inflation deviations were null, which has been considered a special case; and the degree of credibility would be less than unity if lagged inflation deviations were higher than zero, which would be regarded as the general case. Under these two conditions, the degree of credibility would vary from 0 to 1 over time. Moreover, the model also allows the degree of credibility to depend on its own past values through an autoregressive component.

The first step is to define a structural or theoretical equation from which the degree of credibility can be extracted. As the degree of credibility is extracted by a theoretical model and not simply by an index imposing ad hoc conditions, such credibility will be called structural credibility. Moreira (2013a) proposes an expected inflation deviation function, which basically depends on lagged inflation deviations and on the degree of credibility. The equation can assume the following form:

$$
E_{t}\left[\pi_{t+1}\right]=\mu+\left(1-C_{t-1}\right)\left(\pi_{t-1}\right)+\sum_{i=1}^{n} a_{i} \chi i_{t-1}+\varepsilon_{t}
$$

where $E_{t}\left[\pi_{t+1}\right]$ is the expected inflation deviation for period $t+1, C_{t-1}$ is the degree of credibility in period $t-1, \chi$ is the set of control variables such as measure of output and nominal exchange rate, $a_{i}$ is the parameter associated with the control 
variable $i$ and $\varepsilon$ is a stochastic term (a supply shock). ${ }^{1}$

From equation ( 7 ), if credibility in period $t-1$ is maximum $\left(C_{t-1}=1\right)$, then the expected inflation deviation for period $t+1$ depends only on the inflation target and on the set of control variables $\chi$, even if inflation effectively deviates from the target in period $t-1$. In such case, inflation expectations do not depend on observed or lagged inflation, that is, there is no adaptive process in the way expectations are formed and, as a consequence, the inflation dynamics presents null inertia. Otherwise, if $C_{t-1}<1$, the expected inflation deviation is partially or integrally (i.e., for $C_{t-1}=0$ ) dependent on inflation deviation in $t-1$ (along with the control variables). The parameter $\mu$, in turn, could be determined by the degree of credibility and by other idiosyncratic variables with respect to inflation trend.

Equation (7) allows estimating the degree of credibility $C_{t}$. If credibility is low, then it will be possible to identify a strong relation between expected inflation and observed inflation. Otherwise, if the Central Bank is perceived as highly credible, then a weak or even null relationship will be observed between those variables. To measure the monetary policy structural credibility, we should apply some time series method to estimate $\beta=(1-C)$ in equation ( 7$)$. Inference could then be made by having perfect credibility as the null hypothesis $\left(H_{0}: \beta=0\right)$.

As mentioned before, other works on credibility indexes, such as Cecchetti and Krause (2002), impose ad hoc limits or restrictions to normalize the credibility scale from 0 to 1 . Alternatively, in Moreira (2013a,b), such a scale is extracted from the estimated monetary policy structural credibility so that we do not need to impose any arbitrary normalization on it. An example of a previous work in this same spirit is that of Fuhrer (1992). ${ }^{2}$

\subsection{Empirical evidence regarding expected inflation, current inflation, and credibility}

Levin et al. (2004) studied the case for a possible "delink" between expected inflation and lagged inflation by implementing a pooled regression model in which the left-hand side variable is the first difference of inflation expectations and the right-hand side variable is the first difference of lagged effective consumer inflation. The authors found that in non-IT (inflation-targeting) countries there was a highly significant correlation of the expected inflation with a three-year moving average of lagged inflation; but in IT countries expected inflation was better anchored, that is, inflation expectations presented less dependence on lagged or observed inflation.

In turn, Kelly (2008) analyzed relationships between the general public's (and

\footnotetext{
${ }^{1}$ Moreira (2013b) does not include such control variables and shock component in his equation

${ }^{2}$ Although it was applied to a different monetary policy in which the Central Bank's instrument is the money supply and there is no explicit inflation target.
} 
also the professionals') inflation expectations and current inflation in the UK by applying a Granger causality approach. The work found evidence of Granger noncausality from current inflation to the expected one in both sets of expectations during the post-IT period. However, prior to the adoption of IT, the UK economy presented Granger causality from current inflation to inflation expectations, regardless of whether the proxy for inflation expectations was the professionals' or the general public's expectations. These results were interpreted by the author as follows: "The most obvious interpretation of expectations becoming less sensitive to current inflation is that they became anchored to the target (which also suggests that the target was credible) rather than being based on the current rate of RPI inflation itself." (Kelly, 2008, , p. 11).

For the Brazilian case, Minella et al. (2002) estimated the determinants of market participants' inflation expectations using OLS estimates from January 2000 to June 2002. They found statistical significance for the positive effect of inflation targets on expected inflation, while the impacts of lagged inflation on expectations were not significant. Therefore, the authors concluded that inflation targets were appropriately anchoring inflation expectations in Brazil.

In contrast, Carvalho and Bugarin (2006), in a study about the determinants of expected inflation over the period from June 1999 to November 2003, identified nonlinear sensitivity of expected inflation to lagged inflation. They found that not only does such sensitivity increase after November 2002, but also that the role of the inflation target as an attractor for inflation expectations lacks relevance. That could be explained by expressive depreciation of the Brazilian domestic currency given the uncertainties about the future of economic policy. Lowenkron and Garcia (2007) also identified some causality between deviations of the inflation rate from the target and deviations of expected inflation. Those results could be interpreted as evidence of low credibility of the monetary policy in Brazil.

Bevilaqua et al. (2007) found evidence on the role of inflation target as an attractor for inflation expectations during the period from 2000 to 2008. After controlling for important determinants of expectations, such as the exchange rate, they also identified that the sensitivity of expected inflation to lagged inflation increased during political uncertainties in 2002 and 2003. Broadly speaking, the results suggest a gradual gain of credibility by the Brazilian Central Bank, as the sensitivity of expected inflation to observed inflation decreased over the years after the confidence crisis.

Using the copula approach, Moreira et al. (2013) analyzed the dependence between expected inflation and observed inflation in Brazil from January 2005 to June 2011. The results were consistent with other works such as Palma and Portugal (2009), as the dependence structure highlighted a weak relationship between expected and observed inflation, suggesting high monetary policy credibility in Brazil under the inflation-targeting regime.

Thus, taking into account these previous works regarding monetary policy cred- 
ibility, especially in Brazil, it is possible to point out that such a policy increased its credibility over time as the Brazilian inflation-targeting regime was consolidated and, consequently, inflation expectations became more anchored on the inflation target.

\section{Data, Empirical Strategy, and Results}

\subsection{Cointegration and long-term relationships}

We investigated the long-term relationship between expected inflation and its determinants and we used the results to obtain the measure of structural credibility. The time series were collected for the period from January 2005 to July 2012. The following variables were used in this work: EXP_P: accumulated expected inflation for 12 months ahead (Broad Consumer Price Index - Source: Brazilian Central Bank); P: observed inflation (measured by the Broad Consumer Price Index - Source: Brazilian Central Bank); E: the nominal exchange rate (units of domestic currency per US dollar - Source: Brazilian Central Bank); Y: the general industrial production index (Source: Brazilian Institute of Geography and Statistics).

Unit root tests, namely ADF, PP, and DF-GLS (Table A.1 - Appendix), found that the four variables are I(1); so cointegration is an appropriate approach (Engle and Granger, 1987, Johansen, 1991). Thus, cointegration tests following the Johansen procedure (Johansen and Juselius (1990); Johansen op. cit.) were performed. The specification with intercept and without trend was regarded as the best one, according to Akaike and Schwarz criteria (Table A.3 - Appendix). ${ }^{3}$

The Johansen test identified a cointegration relationship between the variables. In turn, trace and maximum eigenvalue tests were applied to determine the number of cointegrating equations. Although the trace test suggested three equations at the $10 \%$ level, the maximum eigenvalue indicated only one equation (Appendix). Therefore, a more parsimonious specification with only one cointegrating equation was chosen as the best option. The model was estimated with the variables in their $\log$ form in order to allow for elasticity relationships. We can observe the estimated cointegrating equation in Table 1.

The estimated coefficients presented statistical significance at $1 \%$ and confirmed some principles of the New Keynesian economics (Clarida et al., 1999). Since the expected inflation equation can be expressed as the iteration of a Phillips curve for periods ahead, one should expect a positive relationship between EXP_P and $\mathrm{P}$ (e.g., a backward-looking Phillips curve), Y and E. In fact, a 1\% increase in observed inflation was contemporaneously followed by a $0.5 \%$ rise in expected inflation. Industrial production has also an important long-term correlation with

\footnotetext{
${ }^{3}$ The first step for testing long-term relationships was to identify the optimal lag order of the unrestricted Vector Autoregressive model, by means of information criteria such as AIC, SIC and HQ, which showed that the best option was to adopt 01 lag in the estimated VAR (Table A.2 - Appendix).
} 
expected inflation: a $1 \%$ increase in the former is accompanied by a $6 \%$ rise in the latter. In turn, the exchange rate has a large impact on expectations: for each $1 \%$ of nominal depreciation there is a $2.24 \%$ increase in expected consumer inflation.

Table 1

Cointegrating Equation: Dependent variable as LOG(EXP_P $)^{4}$

\begin{tabular}{lc}
\hline Independent & Coefficient \\
\hline LOG(P) & 0.503 \\
& $(0.082)$ \\
LOG(Y) & {$[6.068]$} \\
& 6.025 \\
& $(0.971)$ \\
LOG(E) & {$[6.202]$} \\
& 2.240 \\
& $(0.407)$ \\
Constant & {$[5.499]$} \\
& -29.679 \\
& $(4.905)$ \\
& {$[-6.050]$} \\
\hline Note: "( )" for standard error and "[ ]" for $t$-statistic.
\end{tabular}

Source: Data compiled by the authors.

Short-term relationships among the variables can be analyzed through a VEC model, which includes a correction mechanism for disturbances in the long-term equilibrium represented by the cointegrating equation. As long-term equilibrium can be disturbed by unexpected shocks, a short-term reaction in the system might occur to restore the long-term relationship.

Table 2 presents the estimated error correction mechanism. We can observe that industrial production is the correcting variable, since it has a statistically significant coefficient. Indeed, a $1 \%$ cointegration disturbance results in a $0.078 \%$ increase in $\mathrm{Y}$ one month ahead. In other words, it means that the system achieves the entire correction over about 12.6 months.

Figure 1 presents impulse-response functions from the estimated VEC. It is possible to observe that only shocks to observed inflation have statistically significant impacts on expected inflation. That result is consistent with Granger causality tests which show that P, E and Y Granger-cause inflation expectations in the short term jointly (Table A.5 - Appendix), but only P causes EXP_P individually. Such findings indicate that Brazil's monetary policy did not achieve a full degree of credibility over the studied years, as we found sensitivity of expected (E).

${ }^{4}$ In other formal terms, LOG(EXP_P $)=-29.6+0.50$ LOG(P) +6.02 LOG(Y) +2.24 LOG 
Table 2

Error correction mechanism

\begin{tabular}{ccccc}
\hline & $\mathrm{D}($ LOG(EXP_P $))$ & $\mathrm{D}(\mathrm{LOG}(\mathrm{P}))$ & $\mathrm{D}(\mathrm{LOG}(\mathrm{Y}))$ & $\mathrm{D}(\mathrm{LOG}(\mathrm{E}))$ \\
\hline$" u_{t-1} "$ & -0.050956 & 0.004850 & 0.078929 & 0.004423 \\
& $(0.03776)$ & $(0.04216)$ & $(0.01467)$ & $(0.04229)$ \\
& {$[-1.34949]$} & {$[0.11502]$} & {$[5.37896]$} & {$[0.10459]$} \\
\hline
\end{tabular}

Notes: " $u_{t-1}$ " for the cointegration disturbance in the month $t-1$.

"( )" for standard error and "[ ]" for $t$-statistics.

Source: Data compiled by the authors.

inflation to the observed one.

Figure 1

Responses of inflation expectations to impulses in the other variables
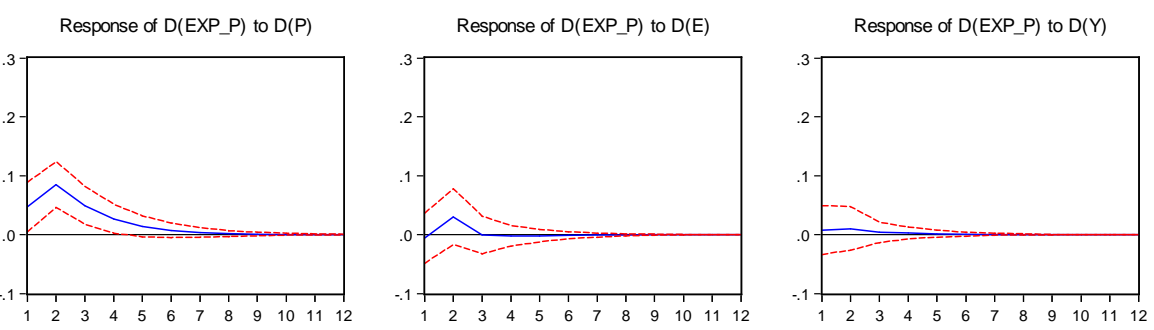

Note:

"D" for the first difference, as the VEC model applies the series in their differences over time. Source: Data compiled by the authors.

\subsection{Monetary policy structural credibility and endogeneity problems}

By taking structural equation (7) and the coefficients of the cointegrating equation estimated in the previous section into account, we can determine the monetary policy structural credibility $(C)$. According to the coefficient of lagged inflation, $\beta$ is equal to 0.503 and, hence, $C$ will be $0.497(\beta=1-C)$. That is consistent with the results of the impulse-response function and the Granger causality tests obtained in the previous section as it suggests that the Brazilian Central Bank has a long way ahead to improve its monetary policy credibility.

Such a value is lower than 0.626 found in Moreira (2013b), which the author regarded as a sign of moderate credibility. The difference between the two values could be attributed to methodological differences. While we have transformed the variables into their log form, Moreira (op. cit.) used first differences. Moreover, not only did we use past inflation as in Moreira (op. cit.), but we also added other 
possible determinants of expected inflation as control variables, namely industrial production and the nominal exchange rate. Therefore, we can regard the current approach as more robust.

In turn, it is possible to argue that the contemporaneous long-term relationship between EXP_P, P, E and Y estimated by the Johansen approach can give room to endogeneity of regressors: for example, an increase in expected inflation can produce higher current inflation, as the forward-looking Phillips curves indicate (Clarida et al., 1999). Accordingly, an increase in expected inflation can induce higher output levels (e.g. by a type of Lucas' curve), although this issue is not consensual for the long term. Also, higher inflation expectations could trigger a depreciation of the domestic currency due to fears of capital losses in hard currency terms from foreign investors.

To overcome that caveat, we can rely on ad hoc regressions using explanatory variables in their lagged form, so that the estimated coefficients translate a predicted relationship (in the Granger sense) between expected inflation and its determinants, instead of a contemporaneous one. With such a transformation, we satisfy the assumption of exogeneity (see Johnston, 1984).

The method for testing cointegration in those simple regressions is that of Engle and Granger (1987) - by testing for unit root in the residual series of the regressions. In order to overcome potential problems arising from heteroskedasticity, autocorrelation, and also endogeneity, the Generalized Method of Moments (GMM, Hansen 1982) was adopted to estimate the equations. For robustness purposes, we estimated three different specifications for the equation. The instrumental variables chosen were the $i$-period lag of the explanatory variables, which, therefore, satisfy the hypothesis of exogeneity of the instruments (Johnston, 1984). To assure the appropriate specification of the instrumental variables, an overidentification analysis was performed by the $J$-test (Cragg, 1983, Hansen, 1982). The results of the GMM estimation are shown in Table 3.

We can observe that inflation expectations have a strong inertial component, as the lagged expected inflation presents a coefficient between 0.79 and 0.88 and with statistical significance at the $1 \%$ level in all models. In turn, a $1 \%$ increase in observed inflation turns into a rise of around $0.1 \%$ in expected inflation one month ahead, while a $1 \%$ increase in industrial production is followed by a rise of $0.33 \%$ to $0.43 \%$ in expected inflation. Regressions 1 and 2 show that the nominal exchange has statistical significance at the $1 \%$ level and that a depreciation of $1 \%$ leads to an increase in expected inflation of around $0.1 \%$. All the three specifications present cointegration and, according to $J$-test, they are specified appropriately. Taking into consideration the fitness to the data criterion, the best specification is the one represented by Regression 3, which contains the one-period lag of expected inflation, observed inflation, and industrial production as explanatory variables together with an intercept. 
Table 3

GMM Estimates: LOG(EXP_P) as Dependent Variable

\begin{tabular}{|c|c|c|c|}
\hline & \multicolumn{3}{|c|}{ GMM estimates } \\
\hline \multirow{4}{*}{ Constant } & 1 & 2 & 3 \\
\hline & $-1.969^{* * *}$ & $-2.220^{* * *}$ & $-1.413^{* * *}$ \\
\hline & $(0.471)$ & $(0.413)$ & $(0.197)$ \\
\hline & {$[-4.171]$} & {$[-5.370]$} & {$[-7.164]$} \\
\hline \multirow[t]{3}{*}{ LOG(EXP_P(-1)) } & $0.883^{* * *}$ & $0.774^{* * *}$ & $0.792^{* * *}$ \\
\hline & $(0.076)$ & $(0.045)$ & $(0.039)$ \\
\hline & {$[11.529]$} & {$[16.904]$} & {$[20.087]$} \\
\hline \multirow[t]{3}{*}{ LOG(EXP_P(-2)) } & -0.114 & & \\
\hline & $(0.077)$ & & \\
\hline & {$[-1.482]$} & & \\
\hline \multirow[t]{3}{*}{$\operatorname{LOG}(\mathrm{P}(-1))$} & $0.119^{* * *}$ & $0.115^{* * *}$ & $0.096^{* * *}$ \\
\hline & $(0.028)$ & $(0.027)$ & $(0.025)$ \\
\hline & {$[4.129]$} & {$[4.265]$} & {$[3.841]$} \\
\hline \multirow[t]{3}{*}{$\operatorname{LOG}(\mathrm{Y}(-1))$} & $0.426^{* * *}$ & $0.477^{* * *}$ & $0.328^{* * *}$ \\
\hline & $(0.092)$ & $(0.080)$ & $(0.040)$ \\
\hline & [4.639] & {$[5.956]$} & {$[8.160]$} \\
\hline \multirow[t]{3}{*}{$\operatorname{LOG}(\mathrm{E}(-1))$} & $0.122^{* * *}$ & $0.131^{* * *}$ & \\
\hline & $(0.045)$ & $(0.045)$ & \\
\hline & {$[2.717]$} & {$[2.892]$} & \\
\hline \multirow{2}{*}{$\begin{array}{c}\text { Adj. } \mathrm{R}^{2} \\
J \text {-statistic }\end{array}$} & 0.908 & 0.905 & 0.913 \\
\hline & 8.298 & 8.817 & 10.032 \\
\hline$J$-statistic ( $p$-value) & 0.297 & 0.277 & 0.282 \\
\hline $\mathrm{EG}(t \text {-statistic })^{*}$ & -7.789 & -7.174 & -7.918 \\
\hline EG (Prob.) & 0.000 & 0.000 & 0.000 \\
\hline
\end{tabular}

Notes: "( )" for standard error and "[ ]" for t-statistic; *** for statistical significance at $1 \%$, $* *$ at $5 \%$ and $*$ at $10 \%$. EG refers to Engle and Granger (1987) critical values, by means of the $\operatorname{ADF}(t$-statistic) unit root test, applied to the residual series from the regression. The instrumental variables in GMM models were C, $\log \left(\exp \_\mathrm{p}(-1)\right), \log \left(\exp \_\mathrm{p}(-2)\right), \log \left(\exp \_\mathrm{p}(-3)\right)$, $\log (\mathrm{p}(-1)), \log (\mathrm{p}(-2)), \log (\mathrm{p}(-3)), \log (\mathrm{y}(-1)), \log (\mathrm{y}(-2)), \log (\mathrm{y}(-3)), \log (\mathrm{e}(-1)), \log (\mathrm{e}(-2)), \log (\mathrm{e}(-$ $3)$ ). 


\subsection{Revised structural credibility and the Kalman Filter with priors}

In this section, we will rely on the coefficients of the GMM estimation in order to recalculate the Brazilian Central Bank's structural credibility $(\mathrm{C})$ and to estimate the time-varying credibility $\left(C_{t}\right)$ through a Kalman filter. Incorporating an autoregressive term into equation (7) leads to the following specification:

$$
E_{t}\left[\pi_{t+1}\right]=\rho E_{t-1}\left[\pi_{t}\right]+(1-\rho)\left[\mu+\left(1-C_{t-1}\right)\left(\pi_{t-1}\right)+\sum_{i=1}^{n} a_{i} \chi_{i_{t-1}}\right]+\bar{\omega}_{t}
$$

Now, the coefficient that relates lagged inflation to the dependent variable becomes $\beta=(1-C)(1-\rho)$, so the structural credibility can be calculated through the simple expression $C=1-[\beta /(1-\rho]$. Using the estimated coefficients of Regression 3, we then have $C=0.538$, which is higher than the value obtained by the non-inertial regression in Section 3.2, but lower than that found in Moreira (2013b) (0.626).

We can also obtain a time-varying path for $C$ using the Kalman filter for the state-space model in equation $(8)^{4}$ following the same line as in Moreira (2013b), but additionally imposing priors for the mean and variance of $\beta$ (0.096 and 0.0006 respectively) from Regression 3. Imposing such priors is important to help with the learning process of the Kalman algorithm, thereby reducing unnecessary volatility of the estimates. Using the formula $C=1-[\beta /(1-\rho]$, it is possible to calculate the path of $C$ from the monthly path of $\beta$ extracted with the Kalman filter.

\section{Specifying the state-space model}

According to Harvey (1989), it is firstly necessary to define the state-space model to apply the Kalman filter. Let us define the observation equation and the system equation as:

$$
\begin{gathered}
J_{t}=z_{t}^{\prime} \theta_{t}+d_{t}+v_{t} \\
\theta_{t}=T_{t} \theta_{t-1}+\eta_{t}
\end{gathered}
$$

where $J_{t}$ stands for the observed variables, which is related to an $m \times 1$ vector, $\theta_{t}$, known as state vector $(t=1, \ldots, T)$; $z_{t}$ is an $N \times m$ matrix, $d_{t}$ represents an $N \times 1$ vector and $v_{t}$ is an $N \times 1$ vector of disturbances with zero mean and covariance $G_{t}$. In turn, although the elements of $\theta_{t}$ are not observable, they are determined by a first-order Markov process, while $T_{t}$ is an $m \times m$ matrix and $\eta_{t}$ is a $b \times 1$ vector of uncorrelated residuals with zero mean and covariance matrix $Q_{t}$. Therefore, the state-space specification assumes the following form (11-16):

$$
J_{t}=E_{t}\left[\pi_{t+1}\right]=\rho E_{t-1}\left[\pi_{t}\right]+(1-\rho)\left(1-C_{t-1}\right)\left(\pi_{t-1}\right)+(1-\rho) \alpha Y_{t-1}
$$

\footnotetext{
${ }^{4}$ To estimate (8) and apply the Kalman filter to it, we specified the regression with the following control variables in the vector $\chi$ : Constant, LOG(EXP_P(-1)), LOG(P(-1)), and LOG(Y(-1)).
} 


$$
\begin{gathered}
z_{t}^{\prime}=\left[\rho E_{t-1}\left[\pi_{t}\right](1-\rho)\left(1-C_{t-1}\right)\left(\pi_{t-1}\right)(1-\rho) \alpha Y_{t-1}\right] \\
\theta_{t}=\left[\begin{array}{c}
\rho_{t} \\
\left(1-\rho_{t}\right)\left(1-C_{t-1}\right) \\
\left(1-\rho_{t}\right) \alpha_{1}
\end{array}\right] \\
T_{t}=\left[\begin{array}{lll}
1 & 0 & 0 \\
0 & 1 & 0 \\
0 & 0 & 1
\end{array}\right] \\
Q_{t}=\left[\begin{array}{ccc}
Q & 0 & 0 \\
0 & Q & 0 \\
0 & 0 & Q
\end{array}\right] \\
{\left[\begin{array}{c}
\rho_{t} \\
(1-\rho)\left(1-C_{t-1}\right) \\
\left(1-\rho_{t}\right) \alpha_{1}
\end{array}\right]=T_{t}\left[\begin{array}{c}
\left(1-\rho_{t-1}\right)\left(1-C_{t-2}\right) \\
\left(1-\rho_{t-1}\right) \alpha_{t-1}
\end{array}\right]+\left[\begin{array}{l}
\eta_{1 t} \\
\eta_{2 t} \\
\eta_{3 t}
\end{array}\right]}
\end{gathered}
$$

After solving this state-space model and extracting the time behavior of by the Kalman filter, we can view the resulting Brazil's path of $C$ on Graph 1.

Graph 1 - Path of Brazil's monetary policy credibility extracted by the Kalman Filter with priors and the HP trend

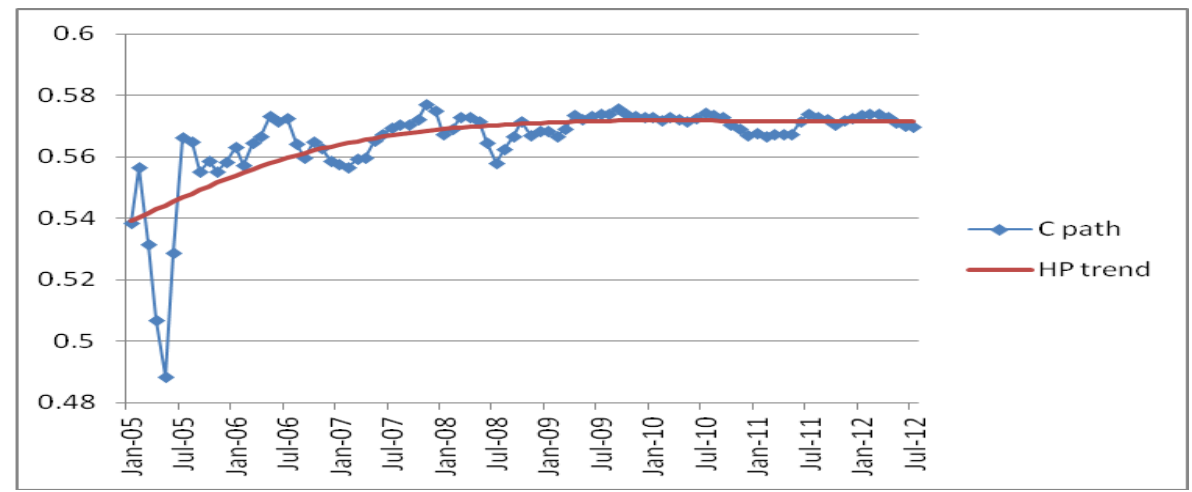

The Kalman filter, as a recursive process (Harvey, 1989), generates more uncertainty for the initial values of the series; so they present higher variance in comparison to the final values. This occurs basically because the initial values are estimated with less information than the final ones. Therefore, we applied the HP (Hodrick-Prescott) filter to the monthly series to smooth out the path of $C$.

Some considerations are noteworthy. First, according to the HP trend for $C$, the degree of credibility attached to the Brazilian monetary policy gradually 
increases from 2005 onwards until it stabilizes at a level of 0.571 over the postsubprime crisis period (2009-2012). That initial increase in monetary policy credibility is associated with the period when inflation was controlled and within the target, which could be attributed to the consolidation of the inflation-targeting regime as well as the sharp appreciation of the Brazilian currency after the boom in commodity prices. Stability enabled faster GDP growth rates and brought optimism to private investments.

In contrast, monetary policy credibility has demonstrated a tendency towards stagnation since 2009. That is potentially related to problems Brazil had to cope with in view of the global financial crisis of 2008 (the US subprime crisis). This post-subprime crisis period was followed by an undervalued domestic currency and lower commodity prices, thereby changing the expectations for the Brazilian economy. However, if one wants to explain why there was such a stagnation of the degree of credibility, it is also important to take into account possible factors relative to economic policy over these last years. Additionally, monetary policy management in Brazil changed substantially after 2011. The Central Bank incorporated an explicit bias towards lower interest rates in its reaction function (Moreira et al., 2013), which led inflation to exceed systematically the inflation target. Indeed, a degree of credibility around 0.5 means that there is still a high correlation between inflation expectations and lagged inflation and, thereby, a large inflationary inertia.

\subsection{Macroeconomic performance and monetary policy credibility}

To what extent does the credibility index explain consumer inflation deviations or other important macroeconomic deviations in Brazil? Conversely, to what extent is credibility explained by these deviations? We can assess these questions through a VAR exercise. Basically, it includes all the variables from the previous regressions (EXP_P, P, E, Y) and $C$ (degree of credibility), extracted in the previous section. However, the observed variables are $I(1)$, while $C$ is $I(0)$ according to ADF, PP and DF-GLS unit root tests. Hence, we estimated the VAR with the $I(1)$ variables in first differences and $C$ in the level. ${ }^{5}$

The dynamic relationship among the selected series was analyzed through generalized impulse-response functions. ${ }^{6}$ The results are presented in Figure 2 and the findings summarized as follows: First, a positive shock to credibility leads both to

\footnotetext{
${ }^{5} \mathrm{~A}$ test for defining the optimal lag order of this VAR has shown that it has one lag (Appendix), but we performed robustness checks by expanding the number of lags. Such a benchmark VAR presents stability as the inverse root test is consistent with all the roots inside the unit circle. Moreover, residual correlation problems (based on the $L M$ test) were corrected by the VAR with six lags, so we used it as the baseline model.

${ }^{6}$ Unlike the conventional method that assumes the Cholesky ordering and is sensitive to reordering of the series (Lutkenpohl, 1991), the generalized impulse-response functions do not have such sensitivity in the VAR (Koop et al., 1996, Pesaran and Shin, 1998) and thus tests for defining the ordering process of the series are avoided.
} 
a decline in expected and observed inflation. Besides, positive shocks to expected and observed inflation are followed by lower credibility levels. The relationships between credibility and inflation by means of the recursive and time-varying method applied in this paper can be translated into a nonlinear dependence or relation (Moreira, 2013a). It means that when there is a positive inflation shock, expected inflation becomes more dependent on lagged inflation levels and thus less anchored on inflation targets, so it is expressed as a declining credibility degree by the current index.

Figure 2

Generalized impulse-response functions for the unrestricted VAR (6) with credibility
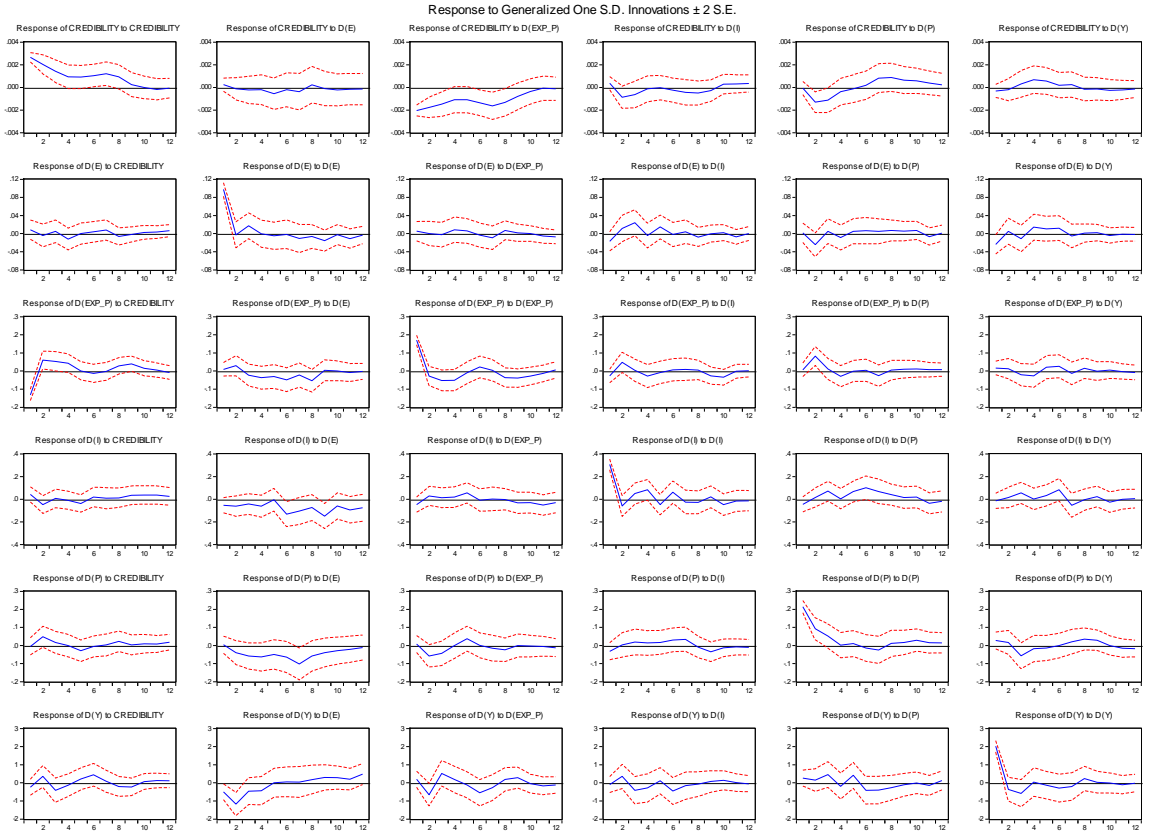

Source: Data compiled by the authors.

The other interesting and statistically significant relationships are:

i) adaptive inflation expectations, which is an expected finding as demonstrated by the GMM estimates;

ii) a positive shock to nominal exchange rate (currency depreciation) is followed by a decrease in industrial output. 
This kind of effect could be associated with the $J$-curve mechanism, ${ }^{7}$ which has been identified in developed economies as well as in emerging markets such as Brazil.

It must be still noted that we could not identify statistically significant impacts of credibility on industrial output. Finally, we can infer that the inflationary process in Brazil is a rigid phenomenon and that output changes do not seem to affect the dynamics of observed and expected inflation with statistical significance.

\subsection{Robustness check}

To test for the regularity of the results in the previous section, some robustness checks were carried out by changing the specification of the baseline VAR. First, we included a general commodity price index denominated in domestic currency ${ }^{8}$ (source: the Brazilian Central Bank). Second, given the pronounced impacts of the subprime crisis on Brazil's economic activity, we added a dummy variable to that expanded model, which assumes the value of one from October 2008 to September 2009, in order to control for that exogenous effect. All these alternative specifications were estimated with the number of lags varying from 1 to 6 . There was no qualitative change in the main findings in comparison with the baseline VAR. Finally, we estimated a Bayesian VAR with Litterman/Minnesota priors that includes the same variables, allowing us to compare its results to the ones observed by the unrestricted VAR.

\subsection{The BVAR model with Litterman/Minnesota priors}

Although VAR models have been very popular in empirical works, Bayesian VAR models have been largely used as a robust alternative to the former. In BVAR models, the parameters are regarded as random variables with prior probabilities (Litterman, 1986). In such a case, it is necessary to adopt a method for estimating priors to be imposed on the mean and the variance of the parameters. Koop and Korobilis (2010) suggest using the Litterman/Minnesota method to estimate priors, even though there exist other possible methods to impose priors, such as Sims-Zha, Plosser-Rebelo, among others. According to Chauvet and Potter (2012), it is implied that the variance-covariance matrix is replaced with an estimation process based on the Kalman filter.

Additionally, the prior mean is considered to be zero and the variancecovariance matrix is assumed to be diagonal (Chauvet and Potter, 2012). The Litterman/Minnesota method is composed of the following priors: $\mu_{1}, \lambda_{1}, \lambda_{2}$, and $\lambda_{3}$ (Liang et al, 2008). $\mu_{1}$ is the prior mean and it is set as zero to lessen the risk of overfitting; $\lambda_{1}$ is the overall tightness of the variance (first lag) and controls for the relative importance of sample and prior information. We defined it as 0.1 so

\footnotetext{
${ }^{7}$ See Bacchetta and Gerlach (1994), Dixit (1994), and Teles (2005).

${ }^{8}$ This variable was included in its first difference as its unit root is based on ADF and PP tests.
} 
as to allow prior information to dominate the sample information; $\lambda_{2}$ represents the relative tightness of the variance of other variables. We defined it as 0.99; $\lambda_{3}$ represents the lag decay and we set it to 1.0 to force a linear decay, following Kadiylaia and Karlsson (1997). The BVAR model was estimated with six lags, following the specification of the baseline model. Its generalized impulse-response functions can be seen in Figure 3.

Figure 3

Generalized impulse-response functions for the BVAR (6) with credibility
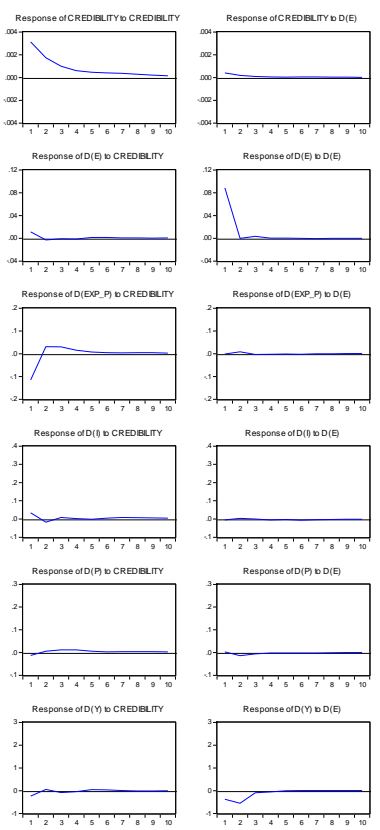
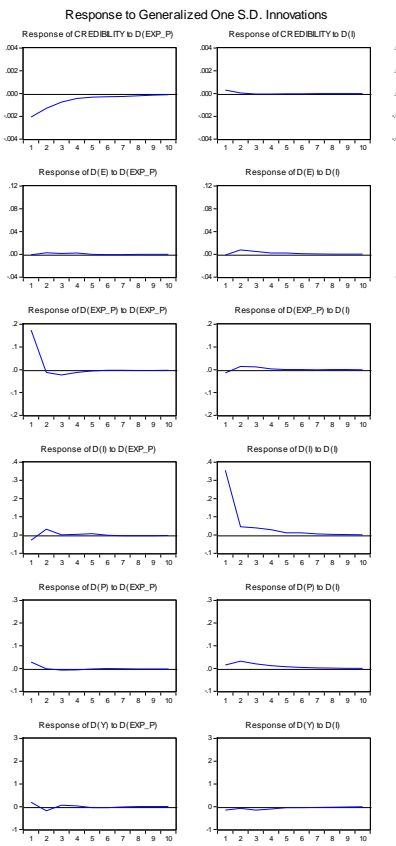
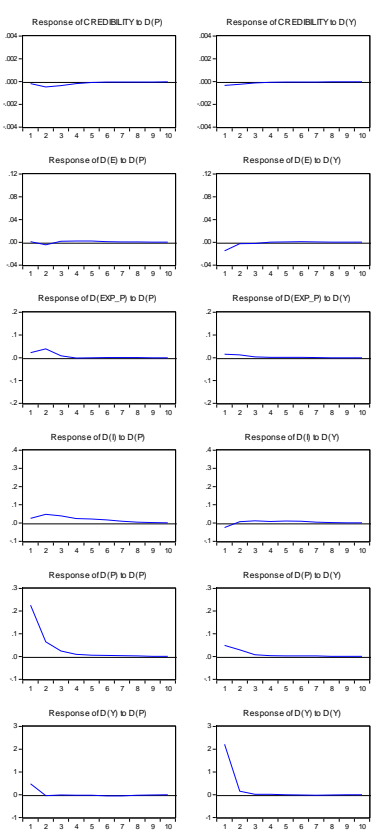

Source: Data compiled by the authors.

The main findings of the BVAR confirm the baseline estimates: both expected and observed consumer inflation changes are negatively affected in the short term by a positive shock to monetary policy credibility in Brazil during the study period. In turn, positive shocks to both expected and effective consumer inflation changes lead to a decline in monetary policy credibility. Such a finding indicates that monetary policy structural credibility in Brazil is not consolidated as it still presents sensitivity to shocks to the inflationary changes. We can also observe that there exists an adaptive expectation regarding the inflationary behavior, as a positive shock to the observed inflation change is accompanied by an increase in expected inflation. 


\section{Concluding Remarks}

This paper is an extension to Moreira's (2013a,b) method for measuring monetary policy structural credibility. Its main advantage compared to other existing methods is that it avoids imposing ad hoc limits to the credibility index. Instead, the Kalman filter approach applied in this work allows monetary policy credibility to be endogenously estimated from the data through a structural model based on the economic theory.

The results for the Brazilian case found in this paper show that monetary policy credibility has a robust impact on inflation dynamics. Conversely, credibility is also affected by inflationary shocks over time. These empirical results are consistent with the theoretical models of Lalonde (2005), Argov et al. (2007), and Moreira (2013a), which broadly point out the existence of mutual causality between credibility and observed inflation. Possible extensions to the current work would be to apply its methodology to other economies and to compare the findings to alternative monetary policy credibility indexes in terms of fitness to data.

\section{References}

Argov, E., Epstein, N., \& Karam, P. (2007). Endogenous monetary policy credibility in a small macro model of Israel. IMF working paper $07 / 207$, International Monetary Fund.

Bacchetta, P. \& Gerlach, S. (1994). Sticky import prices and J-curves. Economics Letters, 44:281-285.

Bevilaqua, A. S., Mesquita, M., \& Minella, A. (2007). Brazil: taming inflation expectations. Working paper series 129, Central Bank of Brazil.

Carvalho, F. \& Bugarin, M. (2006). Inflation expectations in Latin America. Economía, 6:101-145.

Cecchetti, S. G. \& Krause, S. (2002). Central bank structure, policy efficiency and macroeconomic performance: Exploring empirical relationships. Federal Reserve Bank of St. Louis Review, 84:47-60.

Chauvet, M. \& Potter, S. (2012). Forecasting Output, Handbook of Economic Forecasting, volume 2. ScienceDirect.

Clarida, R., Galí, J., \& Gertler, M. (1999). The science of monetary policy: a new Keynesian perspective. Journal of Economic Literature, 37:1661-1707.

Cragg, J. G. (1983). More efficient estimation in the presence of heteroscedasticity of unknown form. Econometrica, 51:751-763.

De Mendonça, H. F. (2004). Mensurando a credibilidade do regime de metas de inflação no Brasil. Revista de Economia Política, 24:344-350. 
Dixit, A. (1994). Hysteresis and the duration of the J-curve. Japan and the World Economy, 6:105-115.

Engle, R. F. \& Granger, C. W. J. (1987). Co-integration and error correction: Representation, estimation and testing. Econometrica, 55:251-276.

Fuhrer, J. C. (1992). Inferring changes in expectation behavior over time: An application of nonlinear time-varying-parameters estimation. Journal of Business \&6 Economic Statistics, 10:169-177.

Hansen, L. P. (1982). Large sample properties of generalized method of moments estimators. Econometrica, 50:1029-1054.

Harvey, A. C. (1989). Forecasting, Structural Time Series Models and the Kalman Filter. Cambridge Univ. Press.

Johansen, S. (1991). Estimation and hypothesis testing of cointegration vectors in Gaussian vector autoregressive models. Econometrica, 59:1551-1580.

Johansen, S. \& Juselius, K. (1990). Maximum likelihood estimation and inference on cointegration: with applications to the demand for money. Oxford Bulletin of Economics and Statistics, 52:169-210.

Johnston, J. (1984). Econometric Methods. McGraw-Hill Book Co, Singapore, 3rd edition.

Kadiylaia, K. R. \& Karlsson, S. (1997). Numerical methods for estimation and inference in Bayesian VAR-models. Journal of Applied Econometrics, 12:99-132.

Kelly, R. (2008). The causal relationship between inflation and inflation expectations in the UK. Discussion paper 24, Bank of England.

Koop, G. \& Korobilis, D. (2010). Bayesian multivariate time series methods for empirical macroeconomics. MPRA Paper 20125, University Library of Munich.

Koop, G., Pesaran, M. H., \& Potter, S. M. (1996). Impulse response analysis in nonlinear multivariate models. Journal of Econometrics, 74:119-147.

Lalonde, R. (2005). Endogenous Central Bank credibility in a small forward looking model of the U.S. economy. Working Paper 2005-06, Bank of Canada.

Levin, A. T., Natalucci, F. M., \& Piger, J. M. (2004). Explicit inflation objectives and macroeconomic outcomes. Working Paper Series 383, European Central Bank.

Litterman, R. (1986). Forecasting with Bayesian vector autoregressions - Five years of experience. Journal of Business and Economic Statistics, 4:25-38. 
Lowenkron, A. \& Garcia, M. G. P. (2007). Monetary policy credibility and inflation risk premium: a model with application to Brazilian data. Discussion Paper 543, Department of Economics PUC-Rio (Brazil).

Lutkenpohl, H. (1991). Introduction to Multiple Time Series Analysis. Springer, Berlin.

Minella, A., de Freitas, P. S., Goldfajn, I., \& Muinhos, M. K. (2002). Inflation targeting in Brazil: Lessons and challenges. Working Paper Series 53, Central Bank of Brazil.

Moreira, R. R. (2013a). The Central Bank's endogenous and non-linear credibility in a dynamic stochastic general equilibrium model: theory and a small computational simulation. International Journal of Computational Economics and Econometrics, 3:2-10.

Moreira, R. R. (2013b). Expected inflation, lagged inflation and the Central Bank's credibility: time-varying and VAR analysis for the recent Brazilian case. The Empirical Economics Letters, 12:619-628.

Moreira, R. R., Chaiboonsri, C., \& Chaitip, P. (2013). Weak dependence between the Brazilian consumer inflation and expected inflation: non-linear and Copulas methods and a note on the Central Bank's credibility. International Journal of Monetary Economics and Finance, 6:40-54.

Palma, A. A. \& Portugal, M. S. (2009). Análise empírica da formação de expectativas de inflação no Brasil: uma aplicação de redes neurais artificiais a dados em painel. Revista de Economia Contemporânea, 13:391-437.

Pesaran, M. H. \& Shin, Y. (1998). Generalized impulse response analysis in linear multivariate models. Economics Letters, 58:17-29.

Svensson, L. E. O. (2000). Open-economy inflation targeting. Journal of International Economics, 50:155-183.

Teles, V. K. (2005). Exchange shocks, monetary policy and external equilibrium of the Brazilian economy in an environment of hysteresis. Economia Aplicada, 9:415-26.

Woodford, M. (2003). Interest and Prices: Foundations of a Theory of Monetary Policy. Princeton University Press, New Jersey. 


\section{Appendix}

Table A.1 - Unit root tests

\begin{tabular}{ccccc}
\hline Variable & ADF $(t$-stat $)$ & PP $($ adj. $t$-stat) & DF-GLS $(t$-stat) & Result \\
\hline EXP_P & -2.811 & -2.929 & -1.284 & $\mathrm{I}(1)$ \\
D(EXP_P $)$ & $-7.635^{* * *}$ & $-7.581^{* * *}$ & $-6.937^{* * *}$ & \\
P & -2.538 & -0.999 & -1.865 & $\mathrm{I}(1)$ \\
D(P) & $-4.822^{* * *}$ & $-4.744^{* * *}$ & $-4.889^{* * *}$ & \\
E & -2.508 & -2.577 & -1.511 & $\mathrm{I}(1)$ \\
D $(\mathrm{E})$ & $-8.922^{* * *}$ & $-8.983^{* * *}$ & $-9.187^{* * *}$ & \\
Y & -1.972 & -2.101 & -2.197 & $\mathrm{I}(1)$ \\
D(Y) & $-8.218^{* * *}$ & $-8.218^{* * *}$ & $-7.594^{* * *}$ & \\
$\mathrm{C}$ & $-3.385^{* *}$ & $-2.941^{* *}$ & $-3.330^{* *}$ & $\mathrm{I}(0)$ \\
\hline Note: ${ }^{*}$ for $10 \%,{ }^{* *}$ for $5 \%$ and ${ }^{* * *}$ for $1 \%$; stands for credibility. &
\end{tabular}

Source: Data compiled by the authors.

Table A.2 - Optimal lag test

\begin{tabular}{clll}
\hline Lag & AIC & SIC & HQ \\
\hline 0 & 8.871090 & 8.987661 & 8.917922 \\
1 & 1.710297 & $2.293150^{*}$ & $1.944454^{*}$ \\
2 & $1.615729^{*}$ & 2.664864 & 2.037213 \\
3 & 1.651608 & 3.167027 & 2.260419 \\
4 & 1.820623 & 3.802324 & 2.616759 \\
5 & 2.102934 & 4.550917 & 3.086397 \\
6 & 2.277256 & 5.191522 & 3.448045 \\
\hline
\end{tabular}

Source: Data compiled by the authors. 
Table A.3 - Optimal specification of the Johansen test

\begin{tabular}{cccccc}
\hline Data Trend: & None & None & Linear & Linear & Quadratic \\
\hline $\begin{array}{c}\text { Rank or } \\
\text { No. of CEs }\end{array}$ & $\begin{array}{c}\text { No Intercept } \\
\text { No Trend }\end{array}$ & $\begin{array}{c}\text { Intercept } \\
\text { No Trend }\end{array}$ & $\begin{array}{c}\text { Intercept } \\
\text { No Trend }\end{array}$ & $\begin{array}{c}\text { Intercept } \\
\text { Trend }\end{array}$ & $\begin{array}{c}\text { Intercept } \\
\text { Trend }\end{array}$ \\
\hline 0 & 2.131924 & 2.131924 & 2.213323 & 2.213323 & 2.260350 \\
1 & 2.102476 & $1.996591^{*}$ & 2.055559 & 2.022221 & 2.054169 \\
2 & 2.137641 & 2.000010 & 2.040314 & 2.002450 & 2.031494 \\
3 & 2.224518 & 2.075532 & 2.097977 & 2.054437 & 2.073713 \\
4 & 2.402761 & 2.194603 & 2.194603 & 2.170338 & 2.170338 \\
\hline \multicolumn{5}{c}{ Schwarz Criteria } \\
\hline & $2.579319^{*}$ & $2.579319^{*}$ & 2.772567 & 2.772567 & 2.931443 \\
2 & 2.773569 & 2.695646 & 2.838501 & 2.833125 & 2.948960 \\
3 & 3.032432 & 2.950725 & 3.046954 & 3.065014 & 3.149982 \\
4 & 3.343006 & 3.277907 & 3.328314 & 3.368661 & 3.415898 \\
\hline & 3.744947 & 3.648637 & 3.648637 & 3.736222 & 3.736222 \\
\hline
\end{tabular}

Source: Data compiled by the authors.

Table A.4 - Cointegration Rank tests

\begin{tabular}{ccccc}
\hline \multicolumn{5}{c}{ Trace } \\
\hline No. of CE(s) & Eigenvalue & Statistic & Critical Value & Prob.** \\
None ${ }^{*}$ & 0.286505 & 66.42162 & 54.07904 & 0.0027 \\
At most $1^{*}$ & 0.180309 & 36.37697 & 35.19275 & 0.0371 \\
At most 2 & 0.119024 & 18.68127 & 20.26184 & 0.0813 \\
At most 3 & 0.079812 & 7.402756 & 9.164546 & 0.1067 \\
\hline \multicolumn{5}{c}{ Maximum Eigenvalue } \\
\hline No. of CE(s) & Eigenvalue & Statistic & Critical Value & Prob.** \\
None ${ }^{*}$ & 0.286505 & 30.04465 & 28.58808 & 0.0323 \\
At most 1 & 0.180309 & 17.69570 & 22.29962 & 0.1944 \\
At most 2 & 0.119024 & 11.27852 & 15.89210 & 0.2319 \\
At most 3 & 0.079812 & 7.402756 & 9.164546 & 0.1067 \\
\hline
\end{tabular}

Source: Data compiled by the authors. 
Table A.5 - Granger causality test for the VEC model regarding D(EXP_P)

\begin{tabular}{|c|c|c|c|}
\hline \multicolumn{4}{|c|}{ Dependent variable: D(EXP_P) } \\
\hline Excluded & Chi-sq & $\mathrm{DF}$ & Prob. \\
\hline $\mathrm{D}(\mathrm{P})$ & 12.56317 & 1 & 0.0004 \\
\hline $\mathrm{D}(\mathrm{E})$ & 0.179664 & 1 & 0.6717 \\
\hline $\mathrm{D}(\mathrm{Y})$ & 0.080655 & 1 & 0.7764 \\
\hline All & 12.70822 & 3 & 0.0053 \\
\hline
\end{tabular}

Source: Data compiled by the authors.

Table A.6 - Optimal lag test for the VAR including C (Credibility)

\begin{tabular}{cccc}
\hline Lag & AIC & SC & HQ \\
\hline 0 & -4.965 .017 & -4.820 .326 & -4.906 .852 \\
1 & $-7.837199^{*}$ & $-6.969050^{*}$ & $-7.488210^{*}$ \\
2 & -7.793 .408 & -6.201 .801 & -7.153 .595 \\
3 & -7.783 .331 & -5.468 .268 & -6.852 .695 \\
4 & -7.580 .950 & -4.542 .429 & -6.359 .490 \\
5 & -7.288 .716 & -3.526 .738 & -5.776 .433 \\
6 & -7.193 .117 & -2.707 .681 & -5.390 .009 \\
\hline
\end{tabular}

Source: Data compiled by the authors. 